\title{
DIE VERNAAMSTE TERME VIR "RYKDOM" \\ IN DIE OU TESTAMENT EN HULLE BETEKENIS-ONTWIK- KELING
}

\author{
DR. W. C. VAN WYK
}

Die begrip „rykdom” word in die literatuur gewoonlik vanuit sy teenstelling „armoede" benader ${ }^{1}$ ). Tog is daar heelwat tekste ir die Ou Testament waarin die terme vir "rykdom" nie in verband met of in teenstelling met die begrip ,armoede" gebruik word nie. Daarom mag dit die wins van perspektief meebring as ons 'n keer die terme vir die begrip „rykdom” ondersoek in die verband waarin hulle in die Ou Testament voorkom. Van hieruit wil ons veral die konklusies trek met betrekking tot die religieuse beoordeling van rykdom in die Ou Testament.

A. Die volgende terme ${ }^{2}$ ) word gebruik om die begrip uit te druk: 'ôn, hôn, hamôn, hajil en 'óšèr.

1. 'ôn. Die oorspronklike betekenis van hierdie woord, waarvan geen Hebreeuse werkwoordsvorm bekend is nie ${ }^{3}$ ), is "verwekkingskrag". Hierdie betekenis is duidelik uit die plekke Gen. 49:3, Deut. 21:17, Ps. 78:51 en Ps. 105:36. In al hierdie tekste word die woord in status constructus-verbinding deur rē'šit, „begin, eersteling" voorafgegaan en in sinonieme paralellelisme met bekôr, ,eersgeborene" gebruik. Die eersgeborene is die eersteling van die verwekkingskrag. Vandaar ontwikkel die betekenis tot „krag, vermoë” oor die algemeen, byvoorbeeld in Job 40:16 (Afr. Vert. 40:11) waar die krag van die seekoei beskryf word en in Jes. 40:26 waar dit in verband met die almag van Jahwè gebruik word. Vandaar ontwikkel dit weer tot „vermoë, rykdom." In laasgenoemde betekenis word dit gebruik in Job 20:10 en besonder duidelik in Hos. 12:9 waar die uitdrukking mās̄ā' 'ôn, „vermoë verkry" parallel aan die gebruiklike werkwoord vir „ryk wees”, naamlik "šr gebruik word:

1) Die Religion in Geschichte und Gegenwart, Tübingen ${ }^{3} 1957$, verwys 'n mens by die trefwoord "Reichtum" na die trefwoord "Armut".

2) Ons verkies om van "terme" of "woorde" te praat, omdat verskillende woorde een en dieselfde begrip kan uitdruk, dikwels sonder enige nuanseverskil.

3) Koehler, Lexicon, s.v. vergelyk wel 'n Arabiese stam wat „rus, vermoeid wees" beteken daarmee. 
„Ja, ek het ryk geword, ek het vir my vermoë verkry"4). Die gebruik van 'ón is hier doelbewus as voorspel met māsā' 'āwôn, in die tweede helfte van die vers.

2.hôn. Hierdie woord kom selde buite die wysheidsliteratuur voor. As werkwoord kom dit net een keer in die Ou Testament voor, naamlik in die Hif'il in Deut. 1:41 in die betekenis van "maklik waan, ligtelik doen". Die stam hou verband met die Arabiese hâna, „lig, maklik wees". Miskien kan ons die grondbetekenis van die stam wat aan hôn ten grondslag lê die beste weergee met ,genoeg wees". Inderdaad word die woord hôn as uitroep gebruik in Spr. 30:15, 16 in die betekenis van ,"genoeg!" Terselfdertyd kan die feit dat een en dieselfde woord gebruik word vir "genoegsaamheid" en ,rykdom" vir ons 'n aanduiding gee van wat onder die begrip ,rykdom" verstaan is, sodat ons nie met 'n betekenis-ontwikkeling van ,genoegsaamheid" tot „rykdom" in die woord hôn moet reken nie. Die Griekse en Siriese vertalings asook die Targum vertaal hôn in Spr. 30:15, 16 met 'arkei, „dis genoeg!" of die ekwivalent daarvan. In Ps. 112:3 en Spr. 8:18 word dit in parallelisme met 'ašèr gebruik. Die vraag kan gestel word of ons in hôn naas 'ôn nie slegs 'n geaspireerde vorm van een en dieselfde woord het nie, soos hêk naas 'êk en hawwâ naas 'awwâ (vergelyk Mig. 7:3). Miskien moet ons op grond van verwante van hôn in die ander Semitiese tale, naamlik Aramees, Siries en Arabies (hoewel die betekenisverwantskap en -ontwikkeling nie baie duidelik is nie) aan hôn as selfstandige en afsonderlike stam vashou. Die feit dat die stam in relatief jong gedokumenteerde tale voorkom kan egter ook as argument gebruik word om die stelling te verdedig dat ons hier juis 'n laat geaspireerde vorm het wat naas en in die plek van die ongeaspireerde vorm in gebrdik gekom het.

3. hămôn. Hierdie woord het 'n interessante betekenisontwikkeling, met die betekenis van "rykdom" aan die einde van die ontwikkeling. Die stam h-m-h (met h-m-m en $\mathbf{h}-\mathbf{w}-\mathbf{m}$ as variante) is waarskynlik klanknabootsing, met ander woorde „hmmm, brom, dreun, druis". Die grondbegrip van hămôn is dus akoesties en nie, soos Koehler meen, aanduiding van 'n opgewonde beweging wat dan ,ins Akutische gewendet" is nie ${ }^{5}$ ). Die Semitiese verwante wat Koehler self by die stam $\mathbf{h}-\mathbf{m}-\mathbf{h}$ aangee asook die oorwig van die plekke waar dit in die Ou Testament voorkom wys baie duidelik op die oorspronklike akoestiese aspek. So kan die betekenisontwikkeling die beste verklaar word. Vanaf die

4) Die Jerusalem Bible vertaal heel plasties: „I have amassed a fortune”.

5) Koehler, Lexicon, s.v. 
geluid (gebrom, gedruis, gedrang) in die besonder van 'n menigte mense ontwikkel dit tot aanduiding van die skare of menigte self. Vanaf ,menigte” is die oorgang maklik na „oorvloed, rykdom". In sommige van die vindplase wat Koehler vir die vertaling „rumoer" of „optog, gevolg" aangee, kan hămôn veel beter met „rykdom" vertaal word, byvoorbeeld Jes. 16:14 waar die Afrikaanse vertaling onverstaanbaar is en 'n vertaling soos die van Van der Flier onbevredigend is, naamlik ,Moabs heerlijkheid met al zijn rumoer wordt niets geacht"'6). Die Septuginta vertaal hier tereg met ploûtos, ,rykdom", in hierdie geval rykdom aan land. bou-oeste. Hoewel hãmôn wat dikwels in Esegiël voorkom meesal in die betekenis "mensemenigte" gebruik word, byvoorbeeld $32: 32$, is die betekenis daarvan in 29:19 en 30:4 ongetwyfeld „rykdom”: „Kyk, Ek gee Egipteland aan Nebukadnesar, die koning van Babel, en hy sal die rykdom daarvan wegdra . . ." (29:19).

Dit word hier saam met „buit” en "roof” gebruik. In die Septuaginta ontbreek die vertalings van die betrokke frase in albei die verse, maar dit is deur Origenes onder asteriskos ingevoeg, egter nie met ploûtos weergegee nie, maar met plêthos, "menigte". Teenoor Koehler moet ons ook stel dat hămôn in Ps. 37:16 en Jes. 60:5 alleen ,rykdom" kan beteken, in die eerste geval as teenstelling tot me'at, "weinig, karig" en in die laaste as parallel vir hajil, „vermoë". In die tekste Pred. 5:9 (parallel kèsèf) en 1 Kron. 29:16 word die betekenis „rykdom" vir hămôn deur niemand in twyfel getrek nie. In albei hierdie gevalle het die Septuaginta met plêthos vertaal.

4. hajil. As werkwoord word die stam slegs twee keer gebruik, in Job 20:21, in die betekenis "duursaam wees", en in Ps. 10:5, waar ons die konjekktuur van die Biblia Hebraica wat in die Afrikaanse vertaling skynbaar gevolg is (,,sy weë is altyd voorspaedig") oorbodig ag. Die betekenis „standvastig, duursaam wees, duur" pas ook hier uitmuntend. Die grondbetekenis van die werkwoord is iets soos "sterk wees", en die selfstandige naamwoord het die betekenis ,,vermoë, krag”. Maar op heelwat plekke het dit ook die betekenis van ,vermoë, rykdom" soos die betekenis van die adjektief hiervan in die Afrikaans duidelik te kenne gee, byvoorbeeld ,'n vermoënde man". In die betekenis van ,eiendom, rykdom" word dit gebruik in onder andere Gen. 34:29, Num. 31:9, Deut. 8:17, 18 en baie duidelik in Jes. 30:6 (as parallel van 'ósār, "skat") en in Jes. 60:5 as parallel van hāmôn jam, „die rykdom van die see". In hierdie verband vermeld ons in die verbygaan

в) R. de Vaux, Hoe het oude Israël leefde, I, Roermond-Maaseik 1961, bl. 130 . 
ook die uitdrukking gibbôr hajil, wat naas „dapper man” eenvoudig as ,grondbesitter" vertaal kan word. Dit is die volle Israelitiese burger wat verplig was tot militêre diens, en omdat hy self vir sy uitrusting moes betaal, 'n sekere welstand moes geniet ${ }^{6}$ ). Omgekeerd het die grondbesit hom op deelname aan oorlog geregtig gemaak, want oorlogvoering was meer voorreg as plig, omdat die oorlogvoering 'n legitieme manier was van selfverryking. So kry 'n mens aandeel aan die buit. Die samehang van grondbesit, burgerskap en krygsdiens het sy oorsprong in die verowering van Kanaăn, waar die grond tussen die families verdeel is.

5. cóšer, (s. nw.), căšîr (adj.) en căšar (ww.) is by uitstek die woordstam wat ,rykdom, ryk, ryk word, ryk wees" in die Ou Testament aandui. In teenstelling met al die voorvermelde stamme het dit nie „rykdom" ens., as afgeleide betekenis nie, maar dit is die primêre betekenis daarvan. Die werkwoord kom in die Qal, Hif ${ }^{c} \hat{l} l$ en Hitpa'ēl-stamformasies voor. Naas absolute gebruik (Jer. 9:22) vind ons die adjektief as teenstelling tot ră'š, ,arm" (2 Sam. 12:1), dal, (Rut 3:10) en 'èbjôn (Ps. 49:3).

Die term kābôd, ,gewig, las, eer" kom enkele kere in die betekenis van "rykdom" voor, veral in die uitdrukking cašâ kābôd, ,rykdom, besittings verwerf” (Gen. 31:1) waar dit op die veelheid van verworwe besittings wys, in oireenstemming met die betekenisontwikkeling van die stam k-b-d van ,swaar" tot „talryk” (byvoorbeeld van die volk, Num. 20:20). Enkele kere word dit ook in parallelisme met 'ošèr gebruik, maar in dergelike gelykte verbindings is dit nie maklik om die presiese nuanse van die woord vas te stel nie. Waarskynlik wys dit meer op die uitwerking van „rykdom” as „glans” of „eer”. Met uitsondering van die paar keer dat die selfstandige naamwoord 'n konnotasie van ,rykdom" kry, is die betekenis van die stam $\mathbf{k - b}-\mathbf{d}$ behalwe waar dit, al na gelang die stamformasie wat gebruik word ,geëer word, geëerd wees, eer" beteken, feitlik altyd ongunstig: „drukkend, lastig, verhard”.

B. Veral in die verbinding van die begrip ,rykdom" met begrippe soos „seën," „wysheid" en „eer" vind ons die positiewe benadering van die $\mathrm{Ou}$ Testament teenoor rykdom uitgedruk. (i) Rykdom en seën:

Dit is veral die Pentateug wat toestande uit die vroeë tyd reflekteer toe rykdom nog geen sosiale probleme meegebring het nie, wat rykdom met die Goddelike seën in verband bring. As die dienaar van Abraham Rebekka, die suster van Laban, as

7) J. P. Oberholzer, Die stam b-r-k in die Semitiese Tale, M.A.-Verhandeling U.P. 
vrou vir Isak gaan vra, sê hy heel aan die begin, net nadat hy homself voorgestel het: ,Die HERE het my heer baie geseën, sodat hy groot geword het, en aan hom kleinvee en beeste, silwer en goud, slawe en slavinne en kamele en esels gegee" (Gen. 24:35). Terselfdertyd leer hierdie teks ons wat onder rykdom as Goddelike seën verstaan is. In Gen. 26:12 word die honderdvoudige oes van Isak in Gerar ook aan Goddelike seën toegeskryf, naas die besit aan vee en bediendes (vs. 14).

Deuteronomium stel hierdie seëninge steeds teen die agtergrond van die gawe van die ryk land Kanaän. Deut. 8:7-19 noem alles wat die land inhou: waterrykdom, graan, vrugtebome, heuning, metale, „'n land waarin jy brood sonder skaarste sal eet, waarin niks jou sal ontbreek nie; . . . en jy sal eet en versadig word en die HERE jou God loof oor die goeie land wat Hy jou gegee het" (vs. 9-10).

Uit hierdie en ander tekste (vgl. veral Deut. 28:1-14) is dit duidelik dat rykdom nie iets is wat verabsoluteer word nie, maar wat altyd met die Gewer daarvan in verband gesien word. Behalwe die stam b-r-k "seën" "' word die werkwoord n-t-n "gee" gebruik, of die Hif. van c-š-r "ryk maak" met Jahwe as subjek. God het aan Salomo rykdom gegee (1 Kon. 3:13); in die lofsang van Hanna lui dit: „Die HERE maak arm en maak ryk" (1 Sam. 2:7) en Spr. 22:2 stel dit op 'n besondere manier: „Ryk en arm ontmoet mekaar, die HERE het hulle almal gemaak." Van Gods kant gesien het die ryke nie voorrang bo die arme nie, en is die arme nie by Hom aanneemliker as die ryke nie. Hoewel dit duidelik gestel word dat God die rykdom gee, hou dit nie in dat die mens hom nie daarvoor inspan nie; inteendeel, rykdom word met vermoeienis verwerf. So sê die Prediker: „Ook vir elke mens aan wie God rykdom en skatte gegee het, en wat $\mathrm{Hy}$ in staat stel om daarvan te eet en sy deel te neem en hom te verheug by sy moeitevolle arbeid, is dit 'n gawe van God' 5:18, vgl. 6:2).

Die vorm wat rykdom aanneem is hoofsaaklik die produkte van die akkerland en die aanteel van die kudde. Hierdie soort rykdom is altyd afhanklik van die gawe van die reën, want daarsonder is geen graanopbrengste moontlik nie en daarsonder kan die weivelde nie die veestapel dra nie (Ps. 65:10 vv.). Die beskrywing van die ryk man in die gelykenis waarmee die profeet Natan koning Dawid tereg gewys het, toon hom as iemand wat menigtes van groot- en kleinvee besit. Tog is die afkeur van hierdie man nie geleë in die rykdom as sodanig wat hy besit nie, maar in die feit dat hy hebsugtig was en nie geskroom het om alles wat die arm man gehad het van bom af weg te neem nie (2 Sam. 12). 
As God die gewer van die rykdom is, is dit vanselfsprekend dat die menslike ywer - hoe noodsaaklik dit ookal is - niks by God se gawe byvoeg nie. Die Spreukeboek bevat waarnemings van die lewenspraktyk en probeer nie altyd om hierdie waarnemings te sistematiseer of religieus te fundeer nie, daarom dat ons oor rykdom heel uiteenlopende uitsprake kan betref. Tog getuig Spr. 10:22 van 'n diepere siening: „Die seën van die HERE - dit maak ryk, en moeitevolle arbeid voeg daar niks by nie." As $\mathrm{Hy}$ die gewer is, spreek dit ook vanself dat hy die rykdom weer kan wegneem (Gen. 31:16).

'n Klassieke formulering oor die rykdom as gawe van God vind ons in die gebed van Dawid voor sy dood, 1 Kron. 29:12, 14 en 16: „Die rykdom en die eer kom van U." Die vrywillige gawes wat die Israeliete vir die tempel gebring het „, kom alles van $U$, en uit $u$ hand het ons dit aan $U$ gegee . . . HERE onse God, hierdie ganse rykdom wat ons berei het om vir $U$, vir $u$ heilige Naam, 'n huis te bou - dit kom uit $u$ hand en dit behoort alles aan U."

\section{(ii) Rykdom en eer:}

„Rykdom en eer" word as vaste verbinding in 2 Kronieke gebruik. Die twee woorde skyn aanvullende of miskien parallelle betekenis te hê. Hierbo het ons die moontlikheid geopper dat met „eer" meer op die uitwerking van die rykdom gewys word. Dit word gewoonlik van dié konings oor wie die Kroniekskrywer gunstig oordeel, dat hulle „gedoen het wat reg was in die oë van die HERE", gesê dat hulle rykdom en eer ontvang het, van Dawid (1 Kron. 29:12), van Josafat (2 Kron. 17:5, 18:1) en van Hiskia (2 Kron. 32:27). Veral uit die laaste geval en uit die geskiedenis van Salomo blyk dat dit min of meer 'n sinoniem vir rykdom is as dit met „rykdom" en ,skatte" saam gegroepeer word: „Ek sal jou ook rykdom en skatte en eer gee” ( 2 Kron. 1:12); „En Jehiskia het buitengewoon baie rykdom en eer besit en vir hom skatkamers gemaak vir silwer en goud en edelgesteentes ... ( 2 Kron. 32:27). Die twee woord word ook in parallelisme gebruik in die halfverse van Spr. 11:6 maar die verhouding tussen die halfverse (sinoniem, antiteties of sinteties) is nie duidelik nie. $\mathrm{Na}$ die omgewing waarin dit staan geoordeel, verwag ons 'n antitetiese parallelisme. Die Septuaginta is van geen hulp nie omdat dit twee halfverse tussen-in invoeg. Driver vertaal: „'n aanvallige vrou verkry eer, maar die kragvolles (căriṣîm) verkry rykdom"8). Ringgren oorweeg 'n teenstelling tussen ,aufrichtiger Güte und unmoralisch $\curvearrowright$ r Kraft beim Streben nach Stellung und

8) H. Ringgren, Sprüche, A.T.D., 1962, bl. 48 n.4. 
Reichtum"'). In albei hierdie gevalle lê die antitese tussen'ēšèt hēn en cărisîm en kan „rykdom" en ,eer" sinoniem opgevat word. (iii) Rykdom en wysheid:

Die verbinding van wysheid en rykdom is die beste uit die lewe van Koning Salomo bekend. Omdat hy wysheid bo rykdom verkies, ontvang hy wysheid én rykdom (1 Kon. 3:11, 13; 2 Kron. 1:11-12). Die beskrywing van Salomo se lewe word prakties afgesluit met die opmerking: „So het koning Salomo dan groter geword as al die konings van die aarde in rykdom en wysheid" 1 Kon. 10:23, 2 Krin. 9:22). Waar dit in verband met Salomo van die begin af as gawes van God gesien is, vind ons in die Spreukeboek dié gedagtegang dat die rykdom die gevolg is van die wys. heid, byvoorbeeld "Die kroon van die wyse is hulle rykdom" (14:24). Hoewel die verkryging van wysheid hoër gestel word as dié van silwer, goud of korale, word van die wyse tog gesê dat „in sy linkerhand rykdom en eer" is (3:13-16). Wanneer die gepersonifieerde wysheid sy uitnodigings doen, vind ons dieselfde paradoksale verbinding: aan die een kant word die wysheid aanloklik gemaak deur te sê dat dit rykdom en eer bring, aan die ander kant word die betreklike waarde van rykdom teenoor wysheid gestel (8:18-19). Prediker 9:11 is maar skynbaar met die gedagte dat rykdom die gevolg is van wysheid in teëspraak: "... dat die wedloop nie is vir die vinniges en die oorlog vir die helde nie; en ook die brood is nie vir die wyse of ook rykdom vir die slimmes" nie . . . Die Prediker wil alleen sê dat dit nie 'n absolute waarborg is dat 'n mens rykdom deur wysheid sal verkry nie. Omdat alles gebeur soos God dit bepaal en omdat God se wil ondeurgrondelik is, kan dit soms 'n keer gebeur dat rykdom nie op wysheid volg nie ${ }^{10}$ ).

C. Rykdom en die wysheidsliteratuur: Ons het tevore reeds opgemerk dat die Wysheidsliteratuur in 'n veelheid van verbande en met verskillende beoordeling die begrip rykdom gebruik. Selde word die waardering vir of die afkeur van rykdom religieus. Veral die Spreukeboek is 'n spieël van die ervaringe in die Israelitiese samelewing, waar al na gelang van die begeleidende omstandighede ' $n$ bepaalde saak sy voor- of nadele het, en positief of negatief beoordeel word. Die arme wat rydom verlang en dit nie het nie, staan net so bloot aan die versoeking om teen die gebod van God te sondig as die een wat rykdom het. Spr. 30:8 illustreer 'n dergelike benadering: „Gee my nie armoede of rykdom nie, laat my geniet die brood wat vir my bestem is, dat ek nie, as ek oorversadig geword het, $U$ verloën nie, en sê: Wie is die

9) Ringgren, a.w., bl. 51.

10) J. van der Ploeg, Prediker, B.O.T., 1953, bl. 58 v. 
HERE? En dat ek nie, as ek arm geword het, steel en my aan die Naam van my God vergryp nie." Dit is 'n gebed om dié deel wat die Skepper in sy wysheid vir die mens bestem het en wat in sy werklike behoefte voorsien. Die gevolge van rykdom kan selfgenoegsaamheid en die vergeet van God wees, en die armoede bring allerlei versoekings soos diefstal en Godslastering. So 'n uitspraak is nie sonder 'n besef van menslike sondigheid nie.

Die reeds vroeër aangehaalde Spr. 22:2 lyk asof dit die onderskeid tussen ryk en arm in die skeppingsordening van God vind, maar dit moet vergelyk word met 14:31 waarin die eis tot barmhartigheid en medelye van die vermoënde teenoor die behoeftige uitdruklik gestel word. Dieselfde gedagte van die plig tot barmhartigheid lê miskien ook agter 29:13, vergelyk ook 28:8b, 27 en 29:7'1). 'n Positiewe beoordeling van rykdom vind 'n mens onregstreeks in uitsprake in die Spreukeboek wat die armoede teken as 'n kwaad wat die mens oor homself bring, soos die bekende Spr. 6:6-11, „Gaan na die mier, luiaard . . ."; vergelyk verder 24:30-34, 26:13-16, 27:23-27. Spr. 10:4 (vgl. 10:15) druk dit kernagtig uit: „Arm is hy wat met 'n trae hand werk; maar die hand van die vlytiges maak ryk." Hoewel armoede die gevolg van luiheid, eiesinnigheid $(13: 4,18)$ en genotsug $(21: 17 ; 23: 21)$ kan wees, kan dit egter ook deur 'n handeling van Jahwe teweeggebring word (1 Sam. 2:7) tot beproewing (Job 1:13-21) en tot loutering (Job 36:15).

In die Wysheidsliteratuur word ook nie nagelaat om op die relatiwiteit van die rykdom te wys nie. In lyn met die vergeldingsdogma wys Elifas, die vriend van Job, daarop dat die goddelose nie ryk bly nie en dat sy vermoë nie stand hou nie (Job 15:29). Selfs Job ondersteun hierdie gedagte in Job 27:13 vv.: die goddelose se rykdom baat hom nie, want hy kom om en andere geniet sy rykdom. Dit is veral die Prediker wat hierdie relatiwiteit onderstreep, vergelyk 5:9 vv. en 6:2 v. In Spreuke het ons ook reeds baie voorbeelde gevind waar geestelike hoër as rykdom gestel word, waarby ons nog 22:1 kan noem: „'n Goeie reputasie is beter as groot rykdom."

D. Rykdom en die profete: Buite die Profete vind ons in die Skrif duidelike spore van 'n profetiese gees. 'n Aanbanende geregtigheidsbegrip vergelykbaar met dié van die profete kan ons al in die Pentateug waarneem. In Gen. 31:16 is dit die mening van Lea en Ragel dat God die rykdim van hulle vader weggeneem het omdat hy hulle verkoop het en die geld deurgebring het. 'n Psalm soos Ps. 49 raak sowcl die wysheid as die profete. Rykdom mag aansien $(49: 19,21)$ en geluk bring (vs. 19) maar die ryke reem niks saam in die dood nie. 'n Kritiese stem gaan op teen 
diegene wat op hulle rykdom vertrou en hulle op hul vermoë beroem (vs. 7). Terselfdertyd is hier die ontwikkeling in die Psalms self bespeurbaar, waarvolgens die ryke meer en meer met die goddelose gelykgestel word ${ }^{12}$ ).

Die profetiese kritiek is nie gerig teen die rykdom as sodanig nie, maar teen die maniere waarop dit verkry is, armes en magteloses uitgebuit is, teen die hoogmoed wat daaruit voortgespruit het, dade en gesindhede wat voortgespruit het uit 'n verkeerde houding teenoor Jahwe, die verbondsgod van Israel. Sag. 11:5 stel op ironiese wyse die ryke aan die kaak wat wel nog die verband tussen Jahwe en sy eie rykdom lê, nog die Godsbetrokkenheid van die rykdom erken, maar die klem van die Gewer na die ontvanger verskuif het. „Loof die Here" is nie 'n lof van God wat op die gawe volg nie, maar wat ter wille van die rykdom uitgespreek word.

Waar die Wysheidsliteratuur reeds gewaarsku het teen die eiewysheid (Spr. 28:11) en onversadigbaarheid (Pred. 4:8) van die rykdom wat tot die ongeluk lei (Pred. 5:12), selfs ook teen die skynrykdom waarby 'n mens voorgee dat jy ryk is (Spr. 13:7), sien die profete die rykdom nie soseer as iets wat die individu raak nie, maar as iets wat sosiale implikasies het. Dit hou ten nouste verband met reg en geregtigheid. In Jer. 9:22 word die ryke gewaarsku om hom nie op sy rykdom te beroem nie, „maar laat hy wat wil roem, hom hierop beroem dat hy verstaan en My ken, dat Ek die HERE is wat goedertierenheid, reg en geregtigheid op die aarde doen; want in diẽ dinge het $\mathrm{Ek}$ 'n behae, spreek die HERE." Male sonder tal word die rykes gegesel oor hulle onreg en bedrog, oor die geweld waarmee hulle hul rykdom vermeerder (Jes. 1:16-17; Jer. 5.27; 17:11; Hos. 12:7-9, Am. 2:6-8. 8:5-6; Miga 2:2, 6:10-12). Hierdeur is die volkssolidariteit verbreek en die HERE geminag, want uit sy vrese vloei die verantwoordelikheid vir die arm volksgenoot voort ${ }^{13}$ ).

E. Konkluderende opmerkings: Die vroeë tyd, veral soos in die aartsvaderverhale weerspieël, beoordeel die rykdom positief. Ook Job word voorgestel as 'n groot grondbesitter asof hy uit die tyd van die aartsvaders afkomstig sou wees. In die ou tyd is daar weinig teenstelling tussen arm en ryk en gevolglik het dit nog geen sosiale vraagstuk geword nie. So min as wat die rykdom in die ouere tekste van die Pentateug, Rigters en Samuel ter sprake kom, so min ook die saak van die armoede.

11) Ringgren, a.w., bl. 113.

12) Vgl. A. Kuschke, Arm und reich im Alten Testament, Z.A.W. 1939, bl. 31-57.

13) Vgl. my (ongepubliseerde) proefskrif: God, volk en mens by die profeet Amos, U.P. 1966, bl. 91-127. 
De Vaux wys daarop dat die opgrawings die beeld van 'n redelike eenvoudige en gelyke lewensstandaard in die vroeë tyd illustreer ${ }^{14}$ ). Byvoorbeeld te Tirsa blyk dit dat die huise van die tiende eeu nie veel van mekaar verskil in afmetings en in wyse van inrigting nie. Die strata van die agste eeu toon 'n duidelike onderskeid in wyke: die wyk waar die huise groter en beter gebou is, is afgesonder van die buurt waarin die huisies dig op mekaar gedring is. In 'n bestek van twee eeue, hoofsaaklik as gevolg van die koningskap en die daarmee gepaardgaande opkoms van 'n klas van amptenare, het daar 'n maatskaplike omwenteling gekom. Die profetiese kritiek is nie teen die omwenteling as sodanig gerig nie, maar teen die luukse wat God vergeet, teen rykdom wat op onregverdige wyse verkry is, teen hebsug, omkopery en onderdrukking en verdrukking van die armes en die swakkes.

Samevattend kan ons die lyn van ontwikkeling so stel: In die voor-Kanaänitiese tyd was rykdom vir Israel veral geleë in die veekuddes. Met die inname van Kanaän het ook die grondbesit groot betekenis verkry. Rykdom is nog nie in breë sosiale verband opgevat nie en beskou as teken van Goddelike welgevalle en seën. Veral die sosiale skade en onreg wat daarmee gepaard gegaan het, veroorsaak die kritiese beoordeling en veroordeling van die profete.

14) De Vaux, a.w., I, bl. 123. 